\title{
Contralateral Adrenal Metastasis After Renal Cell Carcinoma Treatment
}

\author{
Mehmet Balasar ${ }^{\mathrm{a}, \mathrm{c}}$, Abdulkadir Kandemir ${ }^{\mathrm{a}}$, Mahmut Zahid Unlu ${ }^{\mathrm{a}}$, Aykut Yildirim ${ }^{\mathrm{b}}$, Ahmet Tekin ${ }^{\mathrm{b}}$
}

\begin{abstract}
Renal cell carcinoma (RCC) is highly metastasizing. Metastasis may occur synchronously with the primary tumor or in various organs many years after the treatment of the primary RCC. However, isolated contralateral adrenal metastasis (CAM) following the treatment of primary RCC is quite rare. The present study is a case report of a 58 -year-old female patient diagnosed with CAM who had been surgically treated 5 years earlier for primary RCC.
\end{abstract}

Keywords: Renal cell carcinoma; Contralateral adrenal metastasis; Adrenalectomy

\section{Introduction}

Renal cell carcinoma (RCC) makes up to 90-95\% of kidneyoriginated neoplasm. RCC lacks any early warning signs, has various clinical manifestations and is resistant to ionizing radiation therapy as well as chemotherapy. In RCC, one-third of the patients are already suffering from the metastatic disease during the diagnosis and despite of efficient therapy, one-third of the cases develop metastases over time. Despite the fact that RCC can metastasize to almost every organ, the most common organs and areas of metastasis are the lungs, liver, bones, lymph nodes and mediastinum [1]. Adrenal metastases from RCC are also evident in patients who underwent nephrectomy with an incidence of $3 \%$ of solitary adrenal metastasis to the ipsilateral gland and of $0.7 \%$ to the contra lateral gland [2].

\footnotetext{
Manuscript accepted for publication July 04, 2014

aDepartment of Urology, Necmettin Erbakan University Meram Medical School, Konya, Turkey

bDepartment of General Surgery, Necmettin Erbakan University Meram Medical School, Konya, Turkey

${ }^{\mathrm{c} C}$ Corresponding Author: Mehmet Balasar, Department of Urology, Necmettin Erbakan University Meram Medical School, 42080 Akyokus, Konya, Turkey. Email: drbalasar@gmail.com
}

doi: http://dx.doi.org/10.14740/jmc1844w

\section{Case Report}

A mass was determined in the right kidney in the abdominal ultrasound image of a 58-year-old female patient who was referred to the emergency service with intense abdominal pain. Abdominal and pelvic computed tomography (CT) revealed in the middle pole of the right kidney a mass of $50 \times 45 \mathrm{~mm}$. Enhanced CT (dynamic study) with contrast material revealed a mass with necrotic areas, contoured lobules, displaying heterogeneous retention of contrast material. No pathological masses were seen in the other organs in the abdominal CT and X-ray images.

The patient with radiological and clinical RCC diagnosis underwent right flank radical nephrectomy. Tumor was of 50 $\times 45 \mathrm{~mm}$ size and tattletale gray. No adrenal tissue was seen in the specimen. Histopathological analysis made using hematoxylin and eosin stain showed nests of epithelial cells with clear cytoplasm and a distinct cell membrane, separated by a delicate branching network of vascular tissue and thus verified clear cell RCC. The pathology report of the nephrectomy specimen showed a Fuhrman grade 2 stage T1 (T1bN0M0) RCC. The patient did not undergo chemotherapy or immunotherapy during the post-operative period. During the 4 years following the surgical intervention, there were not any pathological findings in the abdominal and thorax CT images. Yet, at the fifth year, a $30 \times 15 \mathrm{~mm}$ mass was seen in the left adrenal gland (Fig. 1). Laboratory analyses, including hormonal examina-

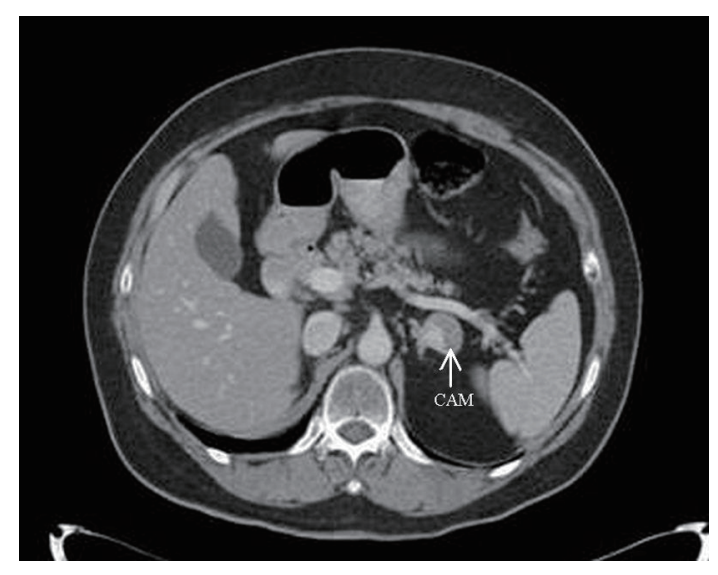

Figure 1. CT images. CAM: contralateral adrenal metastasis. 


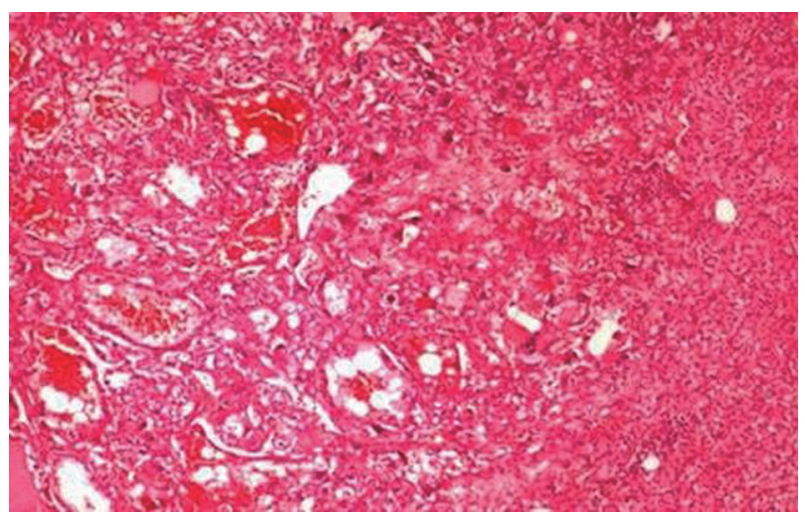

Figure 2. Typical histologic appearance of clear cell renal cell carcinoma on hematoxylin and eosin stain, showing nests of epithelial cells with clear cytoplasm and a distinct cell membrane.

tions, revealed data within normal limits. Likewise, chest CT and bone scintigraphy revealed no abnormal findings. Upon this, the patient underwent left laparoscopic adrenalectomy. The macroscopic tumor size was $30 \times 15 \mathrm{~mm}$ and histopathology analysis enabled metastatic clear cell RCC (Fig. 2). Since the second post-operative period was also uneventful, the patient was discharged on the fourth post-operative day. As her contralateral adrenal mass was a result of systemic metastasis, she was placed on tyrosine kinase inhibitor treatment.

\section{Discussion}

Previously, RCC diagnosis was made based on the classical triad consisting of flank pain, gross hematuria, and the existence of palpable mass. In approximately half of the patients, the metastatic disease was diagnosed. However, with the existence of advanced imaging technologies such as USG, CT, and magnetic resonance (MR), the ratio of coincidentally diagnosed RCC cases varies between $15 \%$ and $60 \%$ [3, 4], with one-third of the patients suffering from the metastatic disease and despite sufficient treatment in one-third of the diagnoses cases metastases will occur [1]. Whereas the high grade of the primary tumor increases metastasis risk, the histopathological subtype (clear cell type mostly to the lungs, papillary to the lymph nodes, and chromophobe to the liver) provides a clue to which sites metastases will occur [5]. The most metastases sites are, according to their ration, the lungs (33-72\%), bones (21-25\%), liver $(5-10 \%)$, intra-abdominal lymph nodes (3$35 \%)$, and brain $(7-13 \%)[6,7]$.

Adrenal metastases from RCC are not uncommon. It is limited with same side adrenal gland malignancy cases with only $1.2-10 \%[8,9]$. Adrenal invasion risk is higher in patients with upper pole tumor or vena cava metastasis $(10 \%)$ [10]. Moreover, contralateral adrenal involvement in RCC is extremely rare. In an autopsy study made with $>400$ RCC patients who had undergone nephrectomy, contralateral adrenal gland was the only site of metastatic involvement in only $2.5 \%$ [2]. Saitoh et al's study made in order to study the frequency of metastasis in RCC patients with a series of 1,828 autopsies revealed that solitary and synchronous CAM was seen only in $0.19 \%$ of the patients [2]. Another retrospective study made with 610 radical nephrectomy cases has shown that CAM incidence was $1.1 \%$ [11] and that all metastases to the contralateral adrenal glands were clear cell tumors. These findings confirm the importance of histological tumor analyses; papillary and chromophobic RCCs have a lower metastatic potential [12]. The tumor in the present case was papillary RCC.

Adrenal metastases most of the time do not show any anatomical and functional symptoms and patients rarely complain about signs of adrenal insufficiency. Single metastasis to the contralateral adrenal gland can lead to uncertainty as the histological status may not be clear [13]. An ideal approach to a solitary contralateral adrenal tumor diagnosis in RCC patients does not exist and differs from the management of "incidentalomas" [14]. Radiological studies may contribute to the preoperative diagnosis, yet, cannot determine definitively if an adrenal tumor in an RCC patient is a primary adrenal neoplasm, an adrenal cortical adenoma, or a metastasis [14]. In the present case, the normal metabolic screen and patient history reaching back to 5 years earlier suggested adrenal metastasis as the most likely diagnosis.

The prognosis of metastatic RCC patients is quite bad; yet, the conception of it has changed dramatically with the emergence of effective treatment method in the prevention of recurrence and metastases. Total resection of isolated metastases has enabled $35-60 \%$ increases in 5-year survival rates and lessened death risk two times [15]. RCC patients with adrenal metastasis only, resection of the adrenal gland are a curative treatment approach and during the follow-ups it was seen that $29-35 \%$ of them survived 5 years or more. Plawner has shown in his study that the 5-year survival of patients operated on for metachronous solitary RCC metastases to the contralateral adrenal gland was lower than that for patients with synchronous adrenal metastases (20\% and $40 \%$, respectively) [16]. Patients who underwent nephrectomy and resection of solitary metastases were reported to have $30 \%$ prolonged survival rates, many of them for more than 5 years.

As in the present case, laparoscopic adrenalectomy for an isolated adrenal metastasis has been accepted as minimally invasive surgery recently. Moreover, it can be performed either with a retroperitoneal or a transperitoneal approach, to minimize possible morbidity further.

\section{Conclusion}

Solitary CAM from RCC is an extremely rare clinical complication that can occur very late following radical nephrectomy. The increased use of radiological diagnostic tests like USG, $\mathrm{CT}$, and MR has led to a more efficient detection of metastatic lesions. Aggressive surgery remains the single treatment option improving prognosis in some of the patients.

\section{References}

1. Montie JE. Follow-up after partial or total nephrectomy for renal cell carcinoma. Urol Clin North Am. 
1994;21(4):589-592.

2. Saitoh H, Nakayama M, Nakamura K, Satoh T. Distant metastasis of renal adenocarcinoma in nephrectomized cases. J Urol. 1982;127(6):1092-1095.

3. Lee CT, Katz J, Fearn PA, Russo P. Mode of presentation of renal cell carcinoma provides prognostic information. Urol Oncol. 2002;7(4):135-140.

4. Bos SD, Mellema CT, Mensink HJ. Increase in incidental renal cell carcinoma in the northern part of the Netherlands. Eur Urol. 2000;37(3):267-270.

5. Hafez KS, Novick AC, Campbell SC. Patterns of tumor recurrence and guidelines for followup after nephron sparing surgery for sporadic renal cell carcinoma. J Urol. 1997;157(6):2067-2070.

6. Mai KT, Landry DC, Robertson SJ, Commons AS, Burns BF, Thijssen A, Collins J. A comparative study of metastatic renal cell carcinoma with correlation to subtype and primary tumor. Pathol Res Pract. 2001;197(10):671-675.

7. Klatte T, Han KR, Said JW, Bohm M, Allhoff EP, Kabbinavar FF, Belldegrun AS, et al. Pathobiology and prognosis of chromophobe renal cell carcinoma. Urol Oncol. 2008;26(6):604-609.

8. Robey EL, Schellhammer PF. The adrenal gland and renal cell carcinoma: is ipsilateral adrenalectomy a necessary component of radical nephrectomy? J Urol. 1986;135(3):453-455.

9. Angervall L, Wahlqvist L. Follow-up and prognosis of renal carcinoma in a series operated by perifascial nephrectomy combined with adrenalectomy and retroperitoneal lymphadenectomy. Eur Urol. 1978;4(1):13-17.

10. Weight CJ, Kim SP, Lohse CM, Cheville JC, Thompson $\mathrm{RH}$, Boorjian SA, Leibovich BC. Routine adrenalectomy in patients with locally advanced renal cell cancer does not offer oncologic benefit and places a significant portion of patients at risk for an asynchronous metastasis in a solitary adrenal gland. Eur Urol. 2011;60(3):458-464.

11. von Knobloch R, Hegele A, Kalble T, Hofmann R. Management of contralateral adrenal metastasis from renal cell carcinoma: possibility of inferior vena cava tumour thrombus. Scand J Urol Nephrol. 2000;34(2):109-113.

12. Cheville JC, Blute ML, Zincke H, Lohse CM, Weaver AL. Stage pT1 conventional (clear cell) renal cell carcinmoa: pathological features associated with cancer specific survival. J Urol. 2001;166(2):453-456.

13. Alkan E, Ozkanli O, Balbay D. Metachronous periadrenal Fatty tissue metastasis from contralateral renal cell carcinoma. Case Rep Urol. 2013;2013:206078.

14. Lau WK, Zincke H, Lohse CM, Cheville JC, Weaver AL, Blute ML. Contralateral adrenal metastasis of renal cell carcinoma: treatment, outcome and a review. BJU Int. 2003;91(9):775-779.

15. Rasco DW, Assikis V, Marshall F. Integrating metastasectomy in the management of advanced urological malignancies-where are we in 2005? J Urol. 2006;176(5):19211926.

16. Plawner J. Results of surgical treatment of kidney cancer with solitary metastasis to contralateral adrenal. Urology. 1991;37(3):233-236. 